Supplement of

\title{
Identification of jet lubrication oil as major component of aircraft exhaust nanoparticles
}

Akihiro Fushimi et al.

5 Correspondence to: Akihiro Fushimi (fushimi.akihiro@nies.go.jp)

\section{Methods}

\subsection{Particle mass}

The particle masses of NanoMoudi II-Au and NanoMoudi II-PC samples were determined from the differences between the weights of the collection substrates before and after the sampling. For the NanoMoudi II-PC samples, only PC filters were weighed after eliminating static electricity using an ion balancer (TAS-182 NWM, Trinc Corp., Shizuoka, Japan). The substrates were weighed with a microbalance (readability $0.1 \mu \mathrm{g}$, UMX 2, Mettler-Toledo, Columbus, OH, USA) in a chamber (CHAM-1000, Horiba) in which the temperature and relative humidity were controlled at $21.5{ }^{\circ} \mathrm{C}$ and $35 \%$, respectively. Each sample was weighed twice, and the obtained results were averaged. If the difference between two recorded weights exceeded $0.5 \mu \mathrm{g}$ in the case of the Au samples or $2.0 \mu \mathrm{g}$ in the case of the PC samples, the sample was reweighed. The samples were not conditioned before the weighing because Au foils and PC filters have low hygroscopicity.

\section{$1.2 \mathrm{EC} / \mathrm{OC}$}

The EC, OC, and total carbon (TC) in the NanoMoudi II-Au samples were determined by using a thermal/optical carbon analyzer (DRI Model 2001 Carbon Analyzer; Desert Research Institute, Las Vegas, NV, USA) (Chow et al., 1993). Threeeighths of each Au-foil sample cut in a fan shape was analyzed after the outside of the deposit area (diameter: $28 \mathrm{~mm})$ had been cut off. The samples were analyzed using the IMPROVE protocol $\left(\mathrm{OC}_{1}: 120{ }^{\circ} \mathrm{C} ; \mathrm{OC}_{2}: 250{ }^{\circ} \mathrm{C} ; \mathrm{OC}_{3}: 450{ }^{\circ} \mathrm{C} ; \mathrm{OC}_{4}\right.$ : $550{ }^{\circ} \mathrm{C}$ [in a $100 \% \mathrm{He}$ atmosphere]; $\mathrm{EC}_{1}: 550{ }^{\circ} \mathrm{C} ; \mathrm{EC}_{2}: 700{ }^{\circ} \mathrm{C} ; \mathrm{EC}_{3}: 800{ }^{\circ} \mathrm{C}$ [in a $2 \% \mathrm{O}_{2} / 98 \%$ He atmosphere] (Chow et al., 2001)). The pyrolysis of the OC during analysis was not corrected because adequate correction using laser light is not possible with Au-foil samples.

\subsection{Elements}

25 The elemental compositions of the NanoMoudi II-PC samples were determined using particle-induced X-ray emission (PIXE) analysis at the Nishina Memorial Cyclotron Center of the Japan Radioisotope Association in Iwate, Japan. The target elements were $\mathrm{Na}, \mathrm{Mg}$, Al, Si, P, S, Cl, K, Ca, Mn, Fe, Co, Ni, Cu, Zn, Ga, As, Se, Br, Sr, Y, Zr, Nb, Mo, Hg, and Pb. The 
NanoMoudi II-PC samples were mounted on a Mylar target frame and bombarded with 2.9-MeV protons from a small cyclotron (Sera et al., 1992). The beam current, accumulated charge, and typical measuring time were 40-60 nA, 20-58 $\mu \mathrm{C}$, and 10-12 min, respectively. The X-ray spectra thus obtained were analyzed using the SAPIX program (Sera et al., 1992). A quantitative analysis of the elemental values was performed using the Nuclepore-Br method (Sera et al., 1997). Blank filters

5 were analyzed in all the procedures. The accuracy of the PIXE analysis was confirmed based on the National Institute of Standards and Technology (NIST) standard reference materials (Saitoh and Sera, 2005).

\section{Results and discussion}

\subsection{Particle number size distribution}

In our parallel measurements at the measurement site, the size distribution and concentrations measured using the EEPS

10 agreed well with those measured using the SMPS for particles larger than $15 \mathrm{~nm}$. A typical example is shown in Fig. S2. However, the EEPS can show an artifact peak at approximately $10 \mathrm{~nm}$ with polydisperse particles, which is not usually observed in the case of the SMPS (Fujitani et al., 2012). Therefore, we treat the EEPS data below $10 \mathrm{~nm}$ as supporting information and indicate it using dashed lines in this paper.

From the measurements obtained using the EEPS, substantial number concentrations of nanoparticles were observed consistently when an aircraft took off or landed while wind was blowing from the runway to the measurement site (Fig. S3). The total particle number concentrations often exceeded $1 \times 10^{6}$ particles $\mathrm{cm}^{-3}$, which is higher than the average concentrations at a roadside with a large amount of heavy-duty diesel vehicles in Kawasaki, Japan in winter $2011\left(1.2 \times 10^{5}\right.$ particles $\mathrm{cm}^{-3}$ (Fujitani et al., 2012)). When the aircraft exhaust plume approached the measurement site, the modal diameters were approximately $10 \mathrm{~nm}$ or smaller, which is smaller than those of diesel vehicle exhaust particles (Fushimi et 20 al., 2011).

The size distributions of particle number concentrations averaged during the sampling periods are shown in Fig. S4 (A). During the daytime sampling periods, the modal diameters were approximately $10 \mathrm{~nm}$ or smaller. In contrast, during the nighttime sampling period, the modal diameter was $34 \mathrm{~nm}$, and the peak concentrations observed $\left(1.1 \times 10^{4}\right.$ particles cm$\left.{ }^{-3}\right)$ were lower than those observed during the daytime $\left(8.8-21 \times 10^{4}\right.$ particles $\left.\mathrm{cm}^{-3}\right)$ by one order of magnitude. These results clearly show that aircraft emissions greatly affect the atmosphere at our sampling site during the daytime sampling periods. We estimated the particle mass concentrations from the measured number concentrations while assuming a density of $1.0 \mathrm{~g}$ $\mathrm{cm}^{-3}$ (Fig. S4 (B, C)). At the nanoparticle size range (stage 11-13), the particle mass concentrations during the daytime were several times those observed during the nighttime. This suggests that aircraft emissions also greatly affect the nanoparticle samples (stage 11-13) during the daytime on mass basis. 


\subsection{Particle mass and chemical components}

The mass concentrations of the particles, OC, EC, sulfur and other elements are shown in Fig. S5 by particle size. Generally, particle mass concentrations showed bimodal distributions with fine mode (diameter: 0.11-0.56 $\mu \mathrm{m})$ and coarse mode (1.0$9.9 \mu \mathrm{m})$. The concentrations of the total particle mass were 9.7-13.4 $\mu \mathrm{g} \mathrm{m}^{-3}$ during the daytime and $10.7 \mu \mathrm{g} \mathrm{m}^{-3} \mathrm{during}$ the

5 nighttime. At the nanoparticle stage (S11-S13, diameter: 10-57 nm), 4-10 $\mu \mathrm{g}$ of the particulate samples per stage were collected, which was assumed to be sufficient for the chemical analyses.

The OC showed not only a fine mode at $0.11-1.0 \mu \mathrm{m}$ but also a nucleation mode at 18-57 nm for the daytime samples \#1 and \#2. The sulfur also showed a bimodal distribution with a nucleation mode at $10-32 \mathrm{~nm}$ and a fine mode in all the daytime samples. In contrast, the EC showed a monomodal distribution with a modal diameter of $0.11-0.56 \mu \mathrm{m}$.

10 In this study, inorganic salts such as nitrate and ammonium were not measured. Thus, large percentages of the particulate mass remained unidentified, especially in the fine and coarse modes. On the other hand, in the nanoparticle size range, NanoMoudi II may have positive artifact on the particulate mass because more than half of the particulate mass often remains unidentified with the measured OC, EC, ions, and elements even in the case of vehicle exhaust particles, of which the major components are supposed to be carbonaceous (Fushimi et al., 2011; Fushimi et al., 2016). In addition, the particle mass concentration at each stage in the nanoparticle size range was approximately 1.4-10 times those estimated from the number concentrations measured using the EEPS (Figs. S4C and S5). Therefore, we assumed that the general chemical characteristics of the nanoparticles can be explained based on the measured components.

The proportions of OC, EC, sulfur, and other elements are shown in Fig. S6 by particle size. For the daytime samples \#1 and \#2, the EC percentages were high (up to $>40 \%$ ) at approximately $0.057-0.29 \mu \mathrm{m}$ (stage $8-10$ ). In contrast, the smaller particles in the nanoparticle size range comprised larger percentages of OC. The OC proportions were approximately 60 $80 \%$ in the nanoparticles $(10-32 \mathrm{~nm})$ of the daytime samples \#1 and \#2. The sulfur and the sum of the other elements comprised approximately $<10 \%$ and 10-30\%, respectively, in the nanoparticles $(10-32 \mathrm{~nm})$ of the daytime samples \#1 and \#2. These results suggest that the nanoparticles emitted from a wide variety of in-use commercial aircraft with high thrusts mainly consist of OC. This is interesting and important because there has been some inconsistency between the volatility of the nanoparticles and the composition of the bulk particles in previous studies. However, if aircraft exhaust nanoparticles primarily comprise OC, the higher volatility appears to be reasonable. The OC proportions can be larger (EC proportions can be smaller) if the pyrolysis that occurs during the carbon analysis is corrected. Furthermore, the masses of the organic materials are generally 1.2-3.1 times that of the OC (Bae et al., 2006), and sulfur and other elements often exist as organic or inorganic compounds. Therefore, the proportion of organic materials, sulfur compounds, and other organic/inorganic elements would be larger than that presented in this paper. 


\section{References}

Bae, M.-S., Schauer, J. J., and Turner, J. R.: Estimation of the Monthly Average Ratios of Organic Mass to Organic Carbon for Fine Particulate Matter at an Urban Site, Aerosol Sci Tech, 40, 1123-1139, 10.1080/02786820601004085, 2006.

Chow, J. C., Watson, J. G., Pritchett, L. C., Pierson, W. R., Frazier, C. A., and Purcell, R. G.: The DRI thermal/optical reflectance carbon analysis system: description, evaluation and applications in U.S. air quality studies, Atmos. Environ., 27A, 1185-1201, 10.1016/09601686(93)90245-t, 1993.

Chow, J. C., Watson, J. G., Crow, D., Lowenthal, D. H., and Merrifield, T.: Comparison of IMPROVE and NIOSH carbon measurements, Aerosol Sci Tech, 34, 23-34, Doi 10.1080/027868201300081923, 2001.

Fujitani, Y., Kumar, P., Tamura, K., Fushimi, A., Hasegawa, S., Takahashi, K., Tanabe, K., Kobayashi, S., and Hirano, S.: Seasonal differences of the atmospheric particle size distribution in a metropolitan area in Japan, The Science of the total environment, 437, 339-347, 10.1016/j.scitotenv.2012.07.085, 2012.

Fushimi, A., Saitoh, K., Fujitani, Y., Hasegawa, S., Takahashi, K., Tanabe, K., and Kobayashi, S.: Organic-rich nanoparticles (diameter: 10-30 nm) in diesel exhaust: Fuel and oil contribution based on chemical composition, Atmos. Environ., 45, 6326-6336, 10.1016/j.atmosenv.2011.08.053, 2011.

15 Fushimi, A., Kondo, Y., Kobayashi, S., Fujitani, Y., Saitoh, K., Takami, A., and Tanabe, K.: Chemical composition and source of fine and nanoparticles from recent direct injection gasoline passenger cars: Effects of fuel and ambient temperature, Atmos. Environ., 124, 7784, 10.1016/j.atmosenv.2015.11.017, 2016.

Saitoh, K., and Sera, K.: Examination of quantitative accuracy of PIXE analysis for atmospheric aerosol particle samples: PIXE analysis of NIST air particulate on filter media, International Journal of PIXE, 15, 59-63, 10.1142/s0129083505000301, 2005.

20 Sera, K., Yanagisawa, T., Tsunoda, H., Futatsugawa, S., Hatakeyama, S., Saitoh, Y., Suzuki, S., and Orihara, H.: Bio-PIXE at the Takizawa facility (Bio-PIXE with a baby cyclotron), International Journal of PIXE, 02, 325-330, 10.1142/s0129083592000348, 1992.

Sera, K., Futatsugawa, S., and Saitoh, K.: Method of quantitative analyis making use of bromine in a nuclepore filter, International Journal of PIXE, 07, 71-85, 10.1142/s0129083597000096, 1997. 


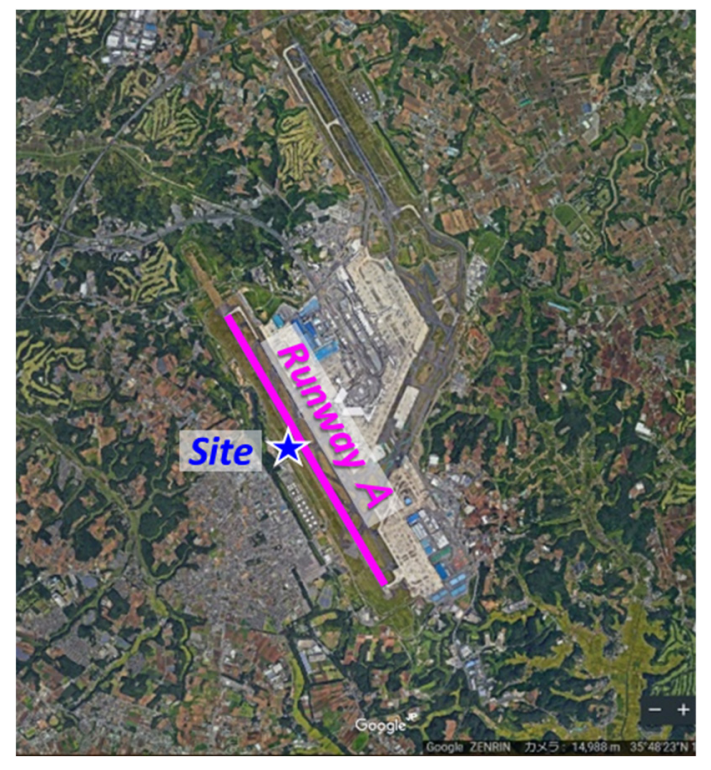

Figure S1: Map of the measurement site. 


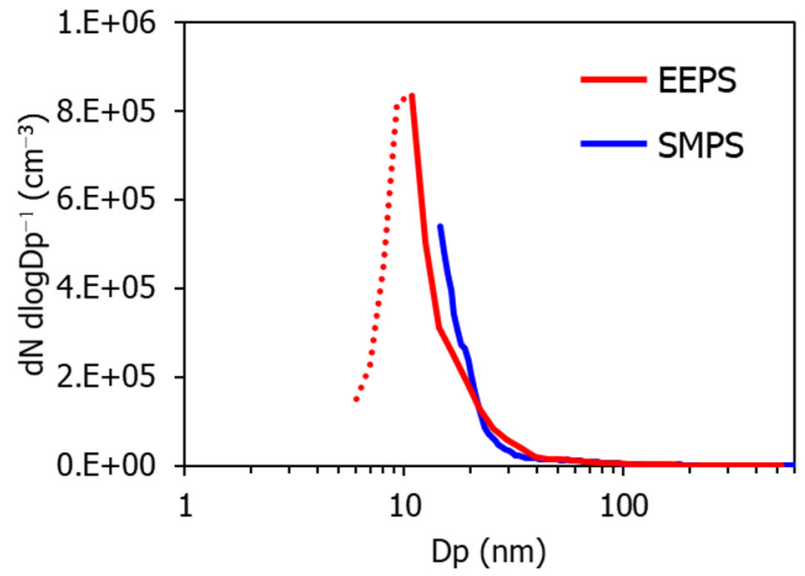

Figure S2: Size distributions of particle number concentrations measured using EEPS and SMPS. Data averaged over $1 \mathrm{~h}$ between 11:00-12:00 on February 15, 2018 are shown. 


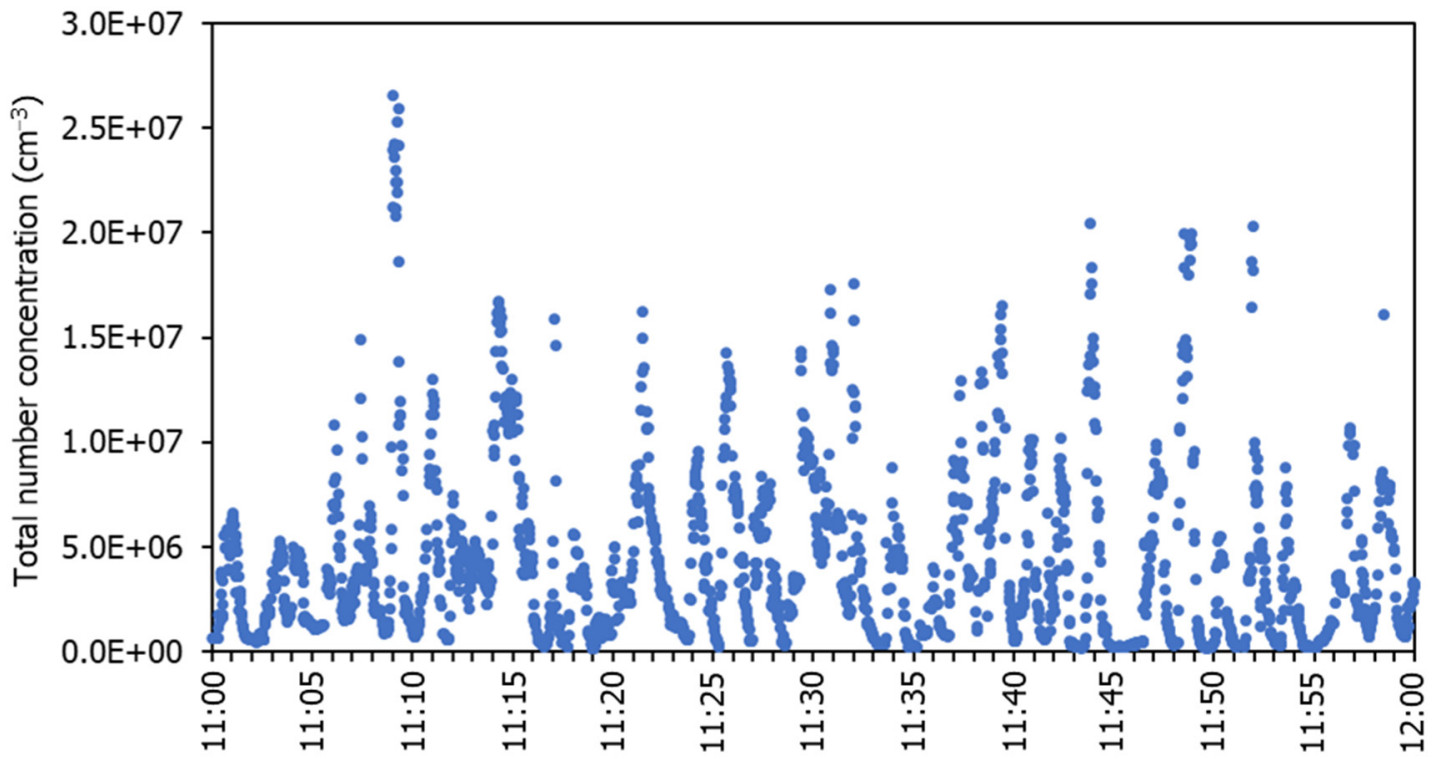

Figure S3: Time series total number concentrations of particles measured using the EEPS between 11:00-12:00 on February 15, 2018. 

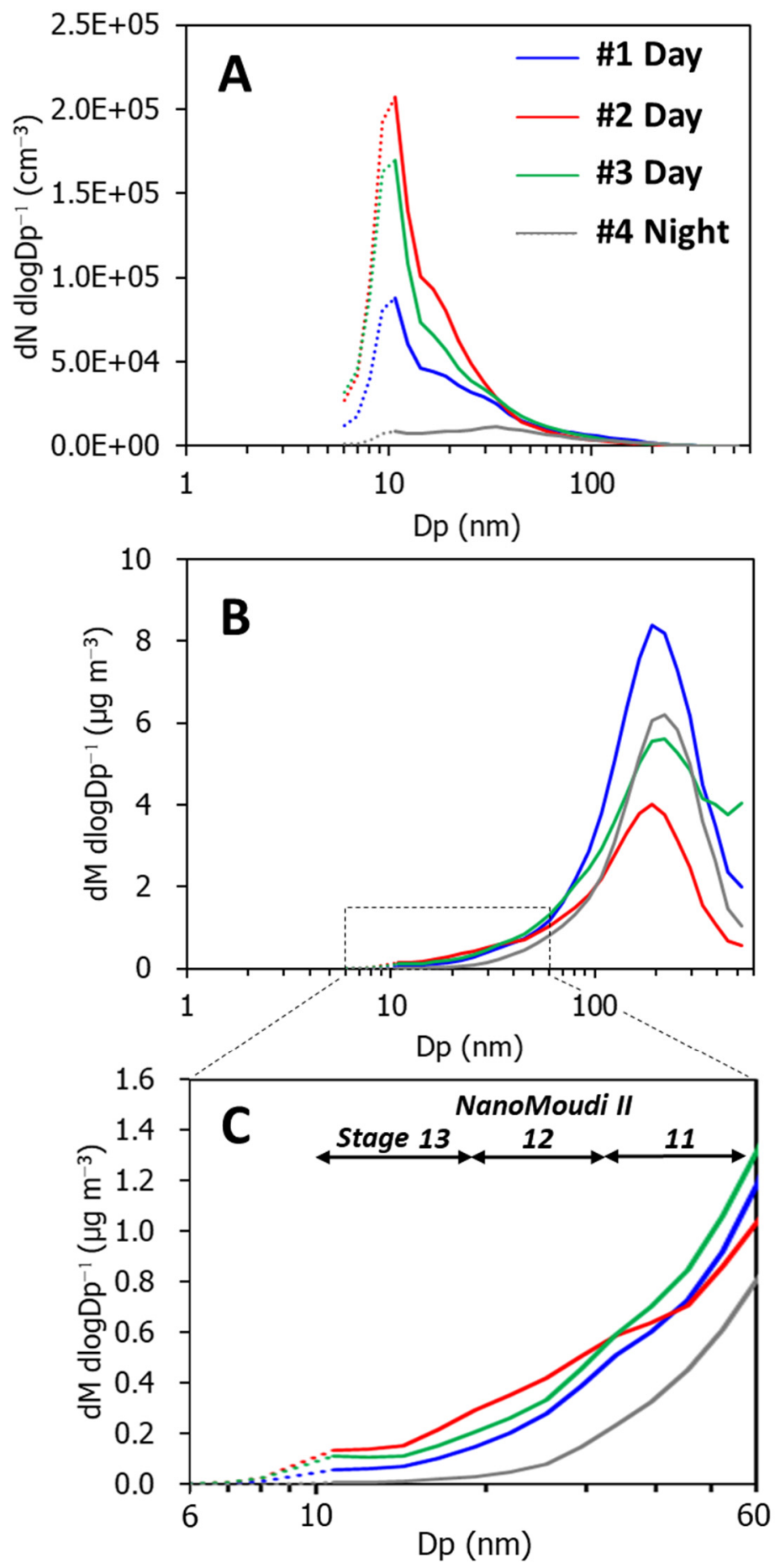

Figure S4: Size distributions of particle number concentrations measured using the EEPS averaged during the sampling periods (A). (B, C) Estimated size distributions of particle mass concentrations. 

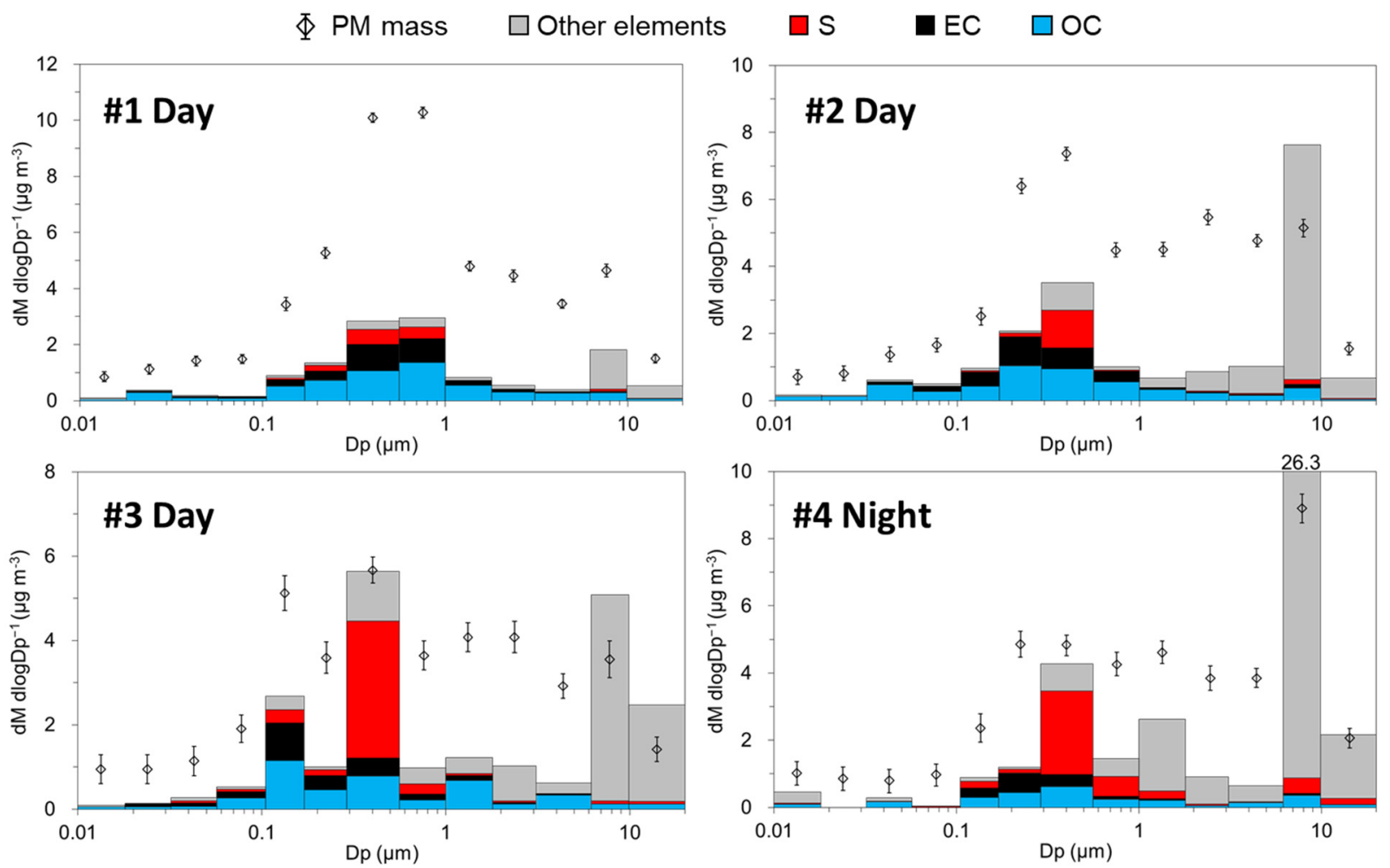

Figure S5: Mass concentrations of particles, OC, EC, sulfur, and other elements by particle size. The data of sulfur and other elements were adjusted so that the particulate masses of the NanoMoudi II-PC samples at each stage are equal to that of the NanoMoudi II-Au samples. 


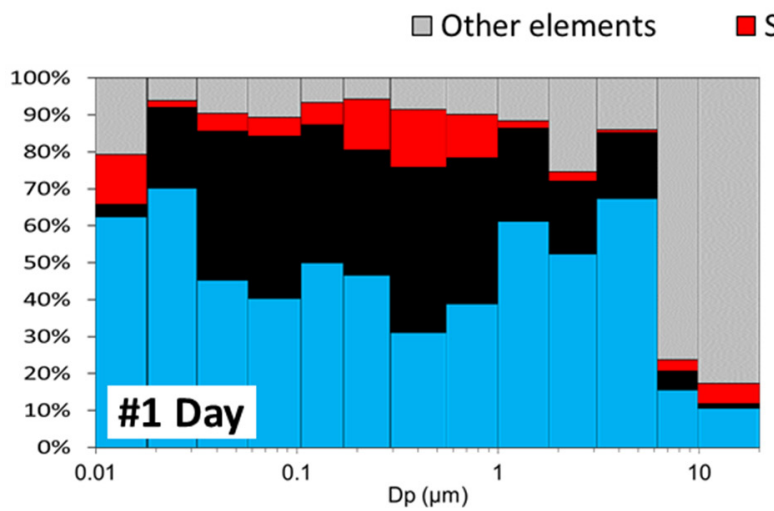

$\square$ EC $\square \mathrm{OC}$
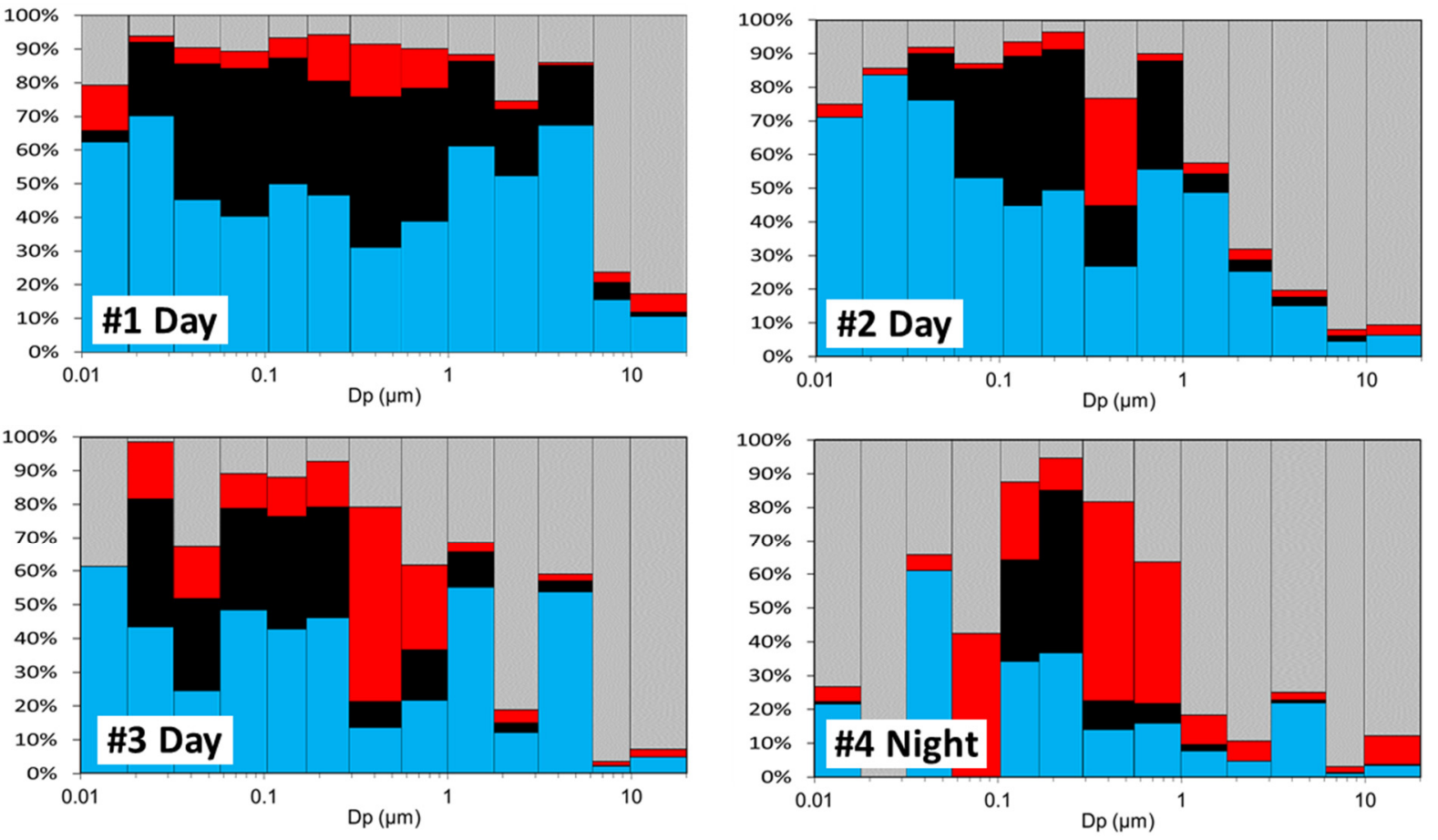

Figure S6: Proportions of OC, EC, sulfur, and other elements by particle size. 